\title{
Desempenho Motor de Aluno com Paralisia Cerebral Discinética Frente à Adaptaçáo das Propriedades Físicas de Recurso Pedagógico ${ }^{1}$ Motor Performance of Students with Dyskinetic Cerebral PALSY AND the Adaptation of Physical Properties of EduCacional Resources
}

\author{
Adriana Garcia GONÇALVES² \\ Lígia Maria Presumido BRACCIALLI ${ }^{3}$ \\ Sebastião Marcos Ribeiro de CARVALHO ${ }^{4}$
}

\begin{abstract}
RESUMO: o objetivo deste estudo foi o de analisar as propriedades físicas modificadas de um recurso pedagógico para facilitação do manuseio de uma criança com paralisia cerebral do tipo discinética. O participante do estudo foi uma criança com paralisia cerebral do tipo discinética com idade de seis anos e matriculada na rede regular de ensino da educaçáo infantil. O recurso pedagógico escolhido foi um jogo de encaixe, em que as propriedades físicas de peso, tamanho e textura foram modificadas. A análise foi feita em relaçấo à qualidade do movimento do membro superior para as variáveis: índice de retidão, deslocamento escalar $(\mathrm{s})$, velocidade média $(\mathrm{Vm})$ e tempo $(\mathrm{t})$. Os resultados evidenciaram que a combinaçáo entre tamanho grande e peso pesado não se mostrou satisfatória, desde a ação de preensão do recurso pedagógico, até o ato de encaixe. Também houve inconsistência nas respostas obtidas nas ações de crianças com paralisia cerebral. Há uma variação nos resultados, sem que ocorra um padrão a ser estabelecido. Desta forma, o presente estudo contribuiu para a compreensẫo das respostas motoras de uma criança com paralisia cerebral do tipo discinética quando submetida à atividade de encaixe com recursos pedagógicos em que as propriedades físicas foram modificadas.
\end{abstract}

PALAVRAS-CHAVE: Educação Especial. Paralisia cerebral. Recurso pedagógico.

\begin{abstract}
The main purpose of this study was to analyze the modified physical properties of an educational resource for facilitating the handling of a child with dyskinetic cerebral palsy. The participant of the study was a six year old child with dyskinetic cerebral palsy enrolled in a regular early childhood education classroom. The educational resource that was selected was a brick game, in which the physical properties of weight, size and texture had been modified. The analysis was made regarding the quality of upper limb movement to the variables: righting index, scalar displacement $(\mathrm{s})$, average speed (As) and time ( $\mathrm{t}$ ). The results showed that combined large size and heavy weight did not have a satisfactory outcome, affecting both grasping the educational resource and fitting. There was also inconsistency in children with cerebral palsy's responses. There is variation in the results, though a standard cannot be established. Thus, this study contributed to understanding the motor responses of a child with dyskinetic cerebral palsy when participating in a fitting activity with educational resources in which the physical properties had been modified.
\end{abstract}

KEYWORDS: Special Education. Cerebral palsy. Educational resource.

\footnotetext{
${ }^{1}$ Apoio: CAPES/PROESP/MEC/SEESP

${ }^{2}$ Doutora em Educação pela Faculdade de Filosofia e Ciências - UNESP - campus de Marília. Professora Adjunta do Departamento de Psicologia - Curso de Licenciatura em Educação Especial e Programa de Pós-Graduaçáa em Educação Especial da Universidade Federal de São Carlos. adrigarcia33@yahoo.com.br

${ }^{3}$ Doutora em Educação Física pela Universidade Estadual de Campinas - UNICAMP. Livre-docente em Reabilitação Física pela Universidade Estadual Paulista - UNESP. Professora Adjunta do Departamento de Educação Especial da Universidade Estadual Paulista Júlio de Mesquita Filho. Programa de Pós-Graduação em Educação - UNESP - Campus Marília.bracci@marilia.unesp.br

${ }^{4}$ Doutor em Energia na Agricultura pela Faculdade de Ciências Agronômicas pela Universidade Estadual Paulista Júlio de Mesquita Filho - UNESP. Professor Assistente Doutor do Departamento de Psicologia da Educação da Faculdade de Filosofia e Ciências - UNESP - campus de Marília. smrc60@gmail.com
} 


\section{Introduçấo}

Muitos termos são designados para referenciar os recursos pedagógicos no contexto da educação infantil. Kishimoto (1994) refere-se à utilização pedagógica do jogo utilizado na escola, no qual representa um recurso educativo, sendo indispensável para o desenvolvimento infantil, cuja especificidade da natureza lúdica seja preservada. Oliveira (1989) destaca que todo brinquedo é educativo, uma vez que apresenta um conjunto de significados implícitos ou explícitos de que a criança se apropria, podendo esta assimilar e transformar tais significados.

De acordo com Araújo e Lorenzini (1995), para se programar atividades pedagógicas para crianças com deficiência física, deve-se prever a dificuldade motora e perceber quais domínios corporais estão presentes.

Para que a criança manipule de forma espontânea um brinquedo, muitas vezes é necessário fazer algumas adaptaçóes para facilitar as formas de manuseio e contato com esse objeto. Assim, materiais são adaptados em relação à forma, textura, peso, na tentativa de minimizar as dificuldades motoras presentes na criança com deficiência física.

A adaptação de materiais para facilitar o manuseio de crianças com deficiência física tem o intuito de promover uma maior independência nas atividades, tanto nas de vida diária, quanto nas escolares. Assim, a escolha dos recursos lúdicos, as formas de utilização, as possibilidades de adaptação do recurso devem ser ofertadas para suprir as reais necessidades da criança, a fim de dar condiçóes e apoio por meio de uma boa estrutura, tanto material como pedagógica e metodológica.

De acordo com Coluccini et al. (2007), estudos apontam que crianças com paralisia cerebral apresentam dificuldade em utilizar os membros superiores em atividade funcionais, sendo que os movimentos apresentam menor velocidade, fraqueza muscular, rigidez mioarticular e coordenação deficitária.

A maioria das crianças com alterações motoras apresenta dificuldade em interagir com o meio devido ao comprometimento motor, pois as dificuldades de manuseio estão presentes na maioria dos casos. Tais dificuldades comprometem o desenvolvimento global da criança, podendo mascarar as potencialidades, ou seja, a sua própria autoexpressão (LORENZINI, 2002).

Martin, Jáuregui e López (2004) elucidam que os recursos didático-pedagógicos requerem adaptaçôes de diversas formas para contemplar as necessidades individuais dos alunos com deficiência física, uma vez que os mesmos apresentam dificuldades em manipular e explorar os objetos por meio dos membros superiores.

Uma das formas de propiciar a inclusão escolar é por meio da alteração do ambiente, levando-se em conta as interaçóes entre o indivíduo e o meio para entendimento das necessidades individuais do aluno com deficiência. Portanto, as adaptaçóes e modificaçóes no meio, desde as arquitetônicas até as mais específicas, como a adaptação de um recurso pedagógico, são essenciais para garantir a acessibilidade de pessoas com deficiência no contexto social e educacional. 
A adaptação de um recurso tem o intuito de promover uma nova situação vivenciada pelo deficiente e, portanto, promover uma série de respostas adaptativas que dependem de vários fatores, como a satisfação com o ato de fazer, o mérito no desempenho ao executar determinada atividade e as experiências positivas e negativas entre a pessoa com deficiência e o meio ambiente (TEIXEIRA; ARIGA; YASSUKO, 2003).

De acordo com Cruz e Emmel (2005), as pesquisas de intervenção com crianças com deficiência têm o intuito de potencializá-las globalmente, no que se referem aos elementos cognitivos, motores, sensoriais, emocionais e sociais.

Especificamente no campo educacional, as adaptaçóes para alunos com deficiência física são necessárias para favorecer a aquisição de conhecimentos. De acordo com Reganhan (2006), para a realização de um trabalho eficaz com estes alunos, torna-se imprescindível conhecer suas reais necessidades e habilidades, bem como conhecer o meio e as possibilidades de ajustes e implementaçóes de recursos e estratégias condizentes, que determinarão um desempenho positivo para a aprendizagem. Com as adaptaçóes realizadas nos recursos pedagógicos, os alunos com deficiência terão mais condiçóes de realizar as atividades propostas pelo professor, como outra criança sem deficiência realiza.

A escolha para adaptação de um recurso não deve ser realizada de maneira imposta, mas o usuário deve também opinar sobre a escolha e o uso do recurso. No contexto escolar, o professor pode propor adaptaçóes, mas sempre solicitar uma opiniāo de seu aluno, buscando investigar as sensaçóes e percepçóes do aluno com o uso do recurso adaptado. Para isso, o professor deve obter conhecimento sobre as propriedades físicas dos objetos e de como as alteraçóes de tais propriedades podem influenciar o desempenho motor de seus alunos com deficiência física. Assim, fica evidente que a escolha do recurso não pode ser realizada de forma aleatória. As adaptaçóes nas propriedades físicas dele têm o intuito de promover condição mais satisfatória de interação da criança com deficiência física com os objetos e auxiliar o professor na escolha do melhor recurso a ser utilizado com seu aluno.

Nessa perspectiva, o presente estudo teve como objetivo analisar as propriedades físicas modificadas de um recurso pedagógico para facilitação do manuseio de criança com paralisia cerebral discinética.

\section{Método}

Participou deste estudo uma criança com paralisia cerebral, com seis anos de idade, que estava matriculada e frequentando a educação infantil em sala regular da rede pública municipal de educação. Os critérios de inclusão foram: criança com diagnóstico clínico de paralisia cerebral discinética, matriculada na rede regular de ensino da educaçáo infantil, com idade entre cinco e seis anos e que não apresentava deficiência auditiva, intelectual ou visual.

A criança recebia atendimento nas diversas áreas da reabilitação em uma clinica escola.

O local de coleta de dados foi o Laboratório de Análise do Movimento - LABAM, após consentimento da Coordenadora do laboratório e do responsável da criança participante 
do estudo e aprovação no comitê de ética ${ }^{5}$. Inicialmente, foi realizada uma avaliação da criança com paralisia cerebral com o objetivo de caracterizar e identificar suas habilidades motoras. Para isso, foi aplicado um Protocolo de avaliação. Além desta classificação geral, foi realizada uma classificação específica pela escala Gross Motor Function Measure Classification System (GMFMCS) (HIRATUKA; MATSUKURA, 2007) com o objetivo de avaliar função motora grossa e pela escala Manual Abilities Classification System (MACS) (ELIASSON, 2006) que mensura o grau de funcionalidade manual de crianças com paralisia cerebral.

Também foi feita a mensuração da mão do participante, ou seja, a antropometria das mãos com as medidas do comprimento longitudinal e transversal com a largura da mão. Outro instrumento utilizado para analisar a forma de preensão entre o polegar com o outro dedo preferido foi uma placa confeccionada em madeira plana, no formato de um prisma triangular, com altura de três $\mathrm{cm}$ e tamanho das arestas de $22 \mathrm{~cm}$, com a demarcação com linhas em intervalos de um cm (HAND, 2002). Foi solicitado ao participante que ajustasse a palma de sua mão de maior habilidade sobre a placa de madeira, de modo que o polegar e o outro dedo, de preferência, pudessem proporcionar uma acomodação confortável para preensão na altura do prisma triangular. Assim, foi possível mensurar a distância, em centímetros, da preensão entre o polegar com o dedo de preferência dos participantes.

O Quadro 1 demonstra a caracterização do participante deste estudo.

Quadro 1 - Caracterização do participante do estudo

\begin{tabular}{|l|l|}
\hline Idade (anos) & seis \\
Gênero & Feminino \\
Distribuição Topográfica & Quadriplegia \\
Tônus Muscular & Distonia \\
Controle de cabeça & Deficitária \\
Controle de tronco & Deficitária \\
Coordenação motora fina & Incoordenada \\
Movimentos involuntários & Atetose \\
GMFMCS & Nível IV \\
MACS & Nível IV \\
Membro superior de maior habilidade & Direito \\
Comprimento longitudinal (cm) & 12,5 \\
Comprimento transversal (cm) & seis \\
Dedos de preferência para preensão & Polegar e Dedo mínimo \\
Medida da distância vertical entre polegar e dedo de preferência (cm) & dois* \\
\hline participante substituiu a preensão do polegar pelo dedo indicador \\
nte própria
\end{tabular}

\subsection{AdAPTAÇÁO do RECURSO PEDAGógico PARA A COLETA DE DADOS}

Foi escolhido um recurso pedagógico de jogo de encaixe que é vendido comercialmente e encontrado nas escolas de educação infantil para que, a partir deste, as propriedades físicas de peso, tamanho e textura fossem modificadas. Trata-se do jogo denominado caixa-encaixe.

A escolha da forma geométrica da peça para o encaixe foi o prisma triangular, pois o instrumento para verificar a preensão do participante era também nesse formato. Assim,

${ }^{5}$ O projeto de pesquisa foi aprovado pelo Comitê de Ética e Pesquisa nome da Instituição, por meio do parecer $n^{\circ} . x x x x / x x x x$. 
na caixa adaptada havia, no tampo, somente o orifício triangular para o encaixe. $\mathrm{O}$ prisma triangular original compunha uma peça maciça com as seguintes características: tamanho quatro e meio $\mathrm{cm}$ para cada aresta e altura de três $\mathrm{cm}$, peso 15,53 gramas, textura MDF, lixado.

A partir do recurso pedagógico original, foram feitas as modificaçóes nas propriedades físicas e que obedeceram aos seguintes critérios:

a) Peso - (leve, pesado) - O critério para o estabelecimento de peso foi que o recurso leve deveria ter, no mínimo, $50 \%$ a menos do peso do recurso original; e o recurso pesado deveria ter, no mínimo, $50 \%$ a mais do peso do recurso original. Outro critério foi a modificação do tipo de material, em que o leve foi confeccionado de isopor, tanto para o tamanho grande, quanto para o pequeno; e o pesado foi confeccionado em chumbo para o recurso pequeno e em madeira maciça para o recurso grande. Para que o peso seja proporcional à alteração do tamanho do recurso, primeiramente foi pesado o recurso pequeno confeccionado em chumbo, para posterior confecção do recurso pesado e grande. Os recursos foram pesados em uma balança de precisão. Este critério de utilização de diferentes materiais para estipular o peso foi estabelecido pensando na possibilidade de que tais materiais são de fácil acesso e possíveis de serem adaptados pelo professor do aluno com deficiência física.

b) Tamanho - (pequeno, grande) - O critério para o estabelecimento do tamanho foi: 50\% menor do que o recurso pedagógico original para o tamanho pequeno e $50 \%$ maior que o original para o tamanho grande. Todos os recursos foram medidos por meio da fita métrica;

c) Textura - (áspera, lisa) - O critério para o estabelecimento da textura foi: áspera com o revestimento do recurso com lixa ${ }^{\circ} .200$ e lisa com o revestimento do recurso com papel espelho. Vários trabalhos utilizaram a lixa no. 200 para designar a textura áspera (PAIVA, 2007).

Foi realizado o cruzamento entre as modificaçóes das propriedades físicas, sempre conservando uma entre as três propriedades, ou seja, peso, tamanho e textura e modificando as demais. Portanto, foram oito o número de combinaçóes, assim foram confeccionados oito recursos pedagógicos com as alteraçóes nas propriedades físicas a partir da análise combinatória realizada. A sequência foi estabelecida a partir de um sorteio para a execução da coleta de dados, apresentada no Quadro 2.

Quadro 2 - Sequência dos recursos pedagógicos adaptados para a coleta de dados

\begin{tabular}{|l|c|c|c|}
\hline \multirow{2}{*}{ Recursos Adaptados } & \multicolumn{2}{|c|}{ Propriedades físicas } \\
\cline { 2 - 4 } & Tamanho & Peso & Textura \\
\hline Recurso 1 & Pequeno (PE) & Leve (LE) & Áspero (AS) \\
\hline Recurso 2 & Grande (GR) & Leve (LE) & Áspero (AS) \\
\hline Recurso 3 & Pequeno (PE) & Pesado (PS) & Liso (LI) \\
\hline Recurso 4 & Pequeno (PE) & Leve (LE) & Liso (LI) \\
\hline Recurso 5 & Grande (GR) & Pesado (PS) & Liso (LI) \\
\hline Recurso 6 & Grande (GR) & Pesado (PS) & Áspero (AS) \\
\hline Recurso 7 & Pequeno (PE) & Pesado (PS) & Áspero (AS) \\
\hline Recurso 8 & Grande (GR) & Leve (LE) & Liso (LI) \\
\hline
\end{tabular}

Fonte própria 
Nas Figuras 1 e 2, são apresentadas a caixa com os tampos e os seus respectivos recursos adaptados para o encaixe e as peças confeccionadas com as modificaçóes nas propriedades físicas.

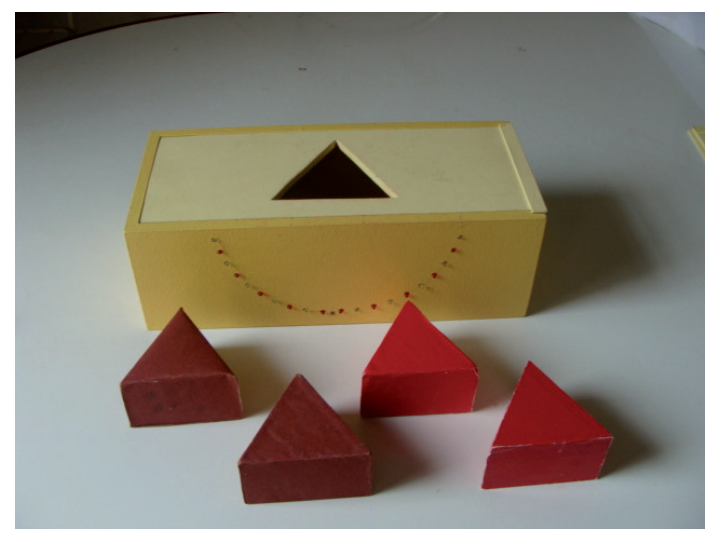

Figura 1 - Recurso pedagógico de encaixe com tampo e peças em prismas triangulares de tamanho grande

Fonte própria

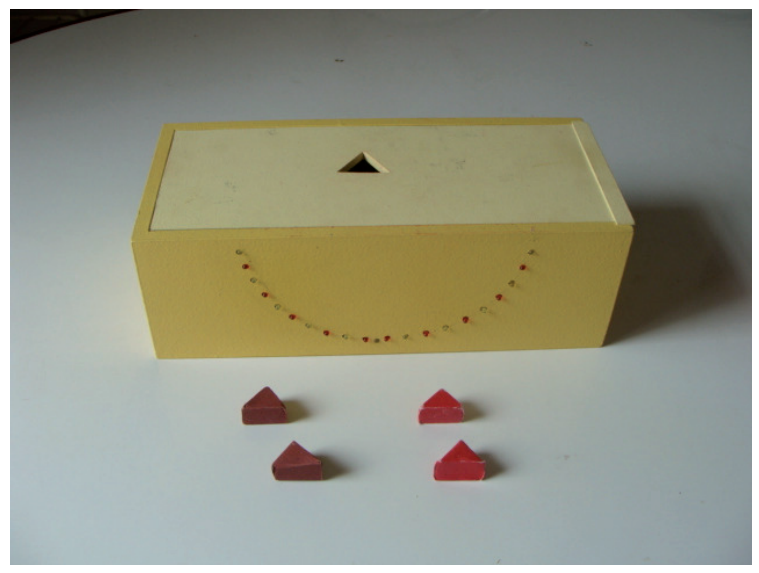

Figura 2 - Recurso pedagógico de encaixe com tampo e peças em prismas triangulares de tamanho pequeno

Fonte própria

\subsection{REgistro PARA A COLETA DE DADOS}

O registro para a coleta de dados ocorreu por meio de um programa computadorizado de análise de movimento denominado Kavídeo, em que é possível reconstruir o movimento em duas dimensóes (2D) e obter os valores de velocidade em cada fração de movimento, denominada frames, o que permitiu calcular a velocidade média $(\mathrm{Vm})$ e o tempo $(\mathrm{t})$, pois a captura de imagem é feita em frames, sendo 60 frames a cada segundo. Além da velocidade média e do tempo, foi possível calcular o deslocamento escalar (s), sendo a velocidade média 
multiplicada pelo tempo e também o índice de retidão, que é calculado dividindo o valor de deslocamento escalar (s) pela distância entre o ponto inicial e final para a execução da atividade.

O membro superior escolhido para a realização da atividade de manipulação do recurso pedagógico foi o com maior habilidade, em que foram colocados marcadores reflexivos em pontos anatômicos sobre a superfície corpórea para a reconstrução do movimento.

\subsection{Procedimentos Para a coleta de dados}

A criança foi posicionada no mobiliário adaptado com cadeira ajustável e mesa com tampo em recorte meia lua, pois, de acordo com Braccialli (2000), esse tipo de tampo propicia uma condição favorável para a execução das atividades escolares por parte da criança com paralisia cerebral.

A criança permaneceu na posição sentada, mantendo os quadris e joelhos fletidos a $90^{\circ}$ e plantas dos pés em apoio. Os membros superiores ficaram apoiados na mesa, sendo um dos membros apenas em apoio na superfície lateral da mesa e o outro membro com maior habilidade; ou seja, aquele usado para execução da tarefa de encaixe, elencado pelo próprio participante, iniciava com a mão apoiada na mesa. Desta forma, o ponto inicial foi demarcado com uma cruz confeccionada com fita adesiva, em que se encontrava a peça para o encaixe, e a mão do participante encontrava-se próxima e paralela à mesma, mantendo o cotovelo fletido. A caixa com o tampo para encaixar a peça estava localizada no alcance médio do participante.

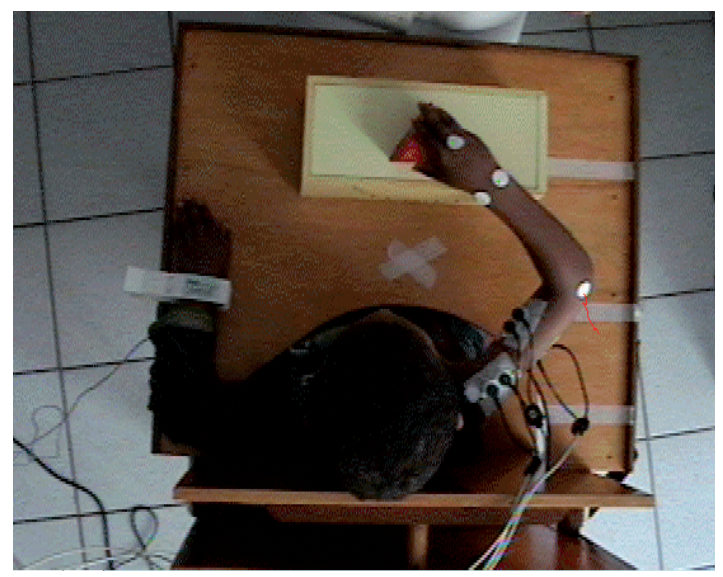

Figura 3 - Demonstrativo do ponto inicial e final (alcance médio) e da escala de polos Fonte própria

Primeiramente, a criança manipulou o recurso pedagógico sem as adaptaçóes, ou seja, o recurso original, com os movimentos de preensão manual, o alcance e o encaixe realizando, assim, a atividade. A repetição do movimento ocorreu cinco vezes. Após este procedimento, 
foram introduzidos cada um dos oito recursos pedagógicos adaptados, ou seja, com as propriedades físicas (peso, tamanho e textura) modificadas. Portanto, a criança manipulou, após as cinco repetiçóes com o recurso original, mais cinco vezes com o recurso adaptado.

O participante realizou 10 movimentos para a realização da atividade de encaixe, para cada recurso. Sendo um total de oito recursos, cada criança realizou, ao final da coleta de dados, um total de, entre recursos originais e adaptados, 80 movimentos de encaixe com o membro superior dominante. Como o número de repetiçóes era expressivo para que a coleta fosse realizada no mesmo dia, esta foi dividida em quatro dias. Assim, era realizada a coleta com dois recursos por dia, num total de 20 movimentos executados pelo participante.

\subsection{ANÁlise dos DADOS}

A análise cinemática para a trajetória do movimento com a manipulação do recurso pedagógico de encaixe foi realizada por meio de quatro variáveis: o tempo em segundos (s), velocidade em metros por segundo $(\mathrm{m} / \mathrm{s})$, o deslocamento em metros $(\mathrm{m})$ e o índice de retidão. O índice de retidão é resultado da medida do deslocamento em metros, dividido pela distância entre o início do movimento até o alvo para o encaixe, também em metros. Portanto, quanto mais próximo do resultado um, maior o índice de retidão, designando um melhor desempenho motor, com exatidão e economia de movimento (CARVALHO, 2004).

Os dados foram tratados por meio da análise estatística descritiva e analítica. Para a análise estatística descritiva, foram utilizados os valores relativos (média) das cinco repetiçóes, tanto para o recurso original, quanto para os adaptados. Para a análise analítica, foi realizada a comparação entre três grupos, ou seja, entre o recurso original com o respectivo recurso adaptado, entre os recursos originais e, por último, entre os adaptados. Para comparação entre os grupos do recurso original com o recurso adaptado, para cada variável numérica estudada, utilizou-se o teste de Wilcoxon para amostras pareadas, sendo o $\mathrm{p} \leq 0,05$ para significância positiva. Para a comparação entre os recursos originais e entre os recursos adaptados, segundo cada variável numérica estudada, utilizou-se a análise de variância não paramétrica de Friedmann para amostras dependentes, sendo o $\mathrm{p} \leq 0,05$ para significância positiva.

\section{Resultados E discussáo}

$\mathrm{Na}$ Tabela 1 é apresentada a média das cinco repetiçóes com os recursos originais e com os adaptados para as variáveis analisadas: índice de retidão, deslocamento escalar (s), velocidade média $(\mathrm{Vm})$ e tempo $(\mathrm{t})$. 
Tabela 1 - Valores relativos (média) para as variáveis índice de retidão, deslocamento escalar (s), velocidade média $(\mathrm{Vm})$ e tempo despendido para o deslocamento $(\mathrm{t})$, tanto para o recurso original, quanto para os adaptados

\begin{tabular}{|c|c|c|c|c|}
\hline & Índice de retidão & $\begin{array}{l}\text { Deslocamento escalar } \\
\text { (s) em metros }(\mathbf{m})\end{array}$ & $\begin{array}{l}\text { Velocidade Média } \\
(\mathrm{Vm}) \text { em metros por } \\
\text { segundo }(\mathrm{m} / \mathrm{s})\end{array}$ & $\begin{array}{l}\text { Tempo }(t) \text { em } \\
\text { segundos }(s)\end{array}$ \\
\hline Original & 17,20 & 2,75 & 0,20 & 13,03 \\
\hline Adap recurso 1 (PE/LE/AS) & 9,50 & 1,52 & 0,17 & 8,80 \\
\hline Original & 11,42 & 1,83 & 0,26 & 7,43 \\
\hline Adap recurso 2 (GR/LE/AS) & 16,41 & 2,62 & 0,18 & 14,83 \\
\hline Original & 13,94 & 2,23 & 0,19 & 12,30 \\
\hline Adap recurso 3 (PE/PS/LI) & 9,11 & 1,45 & 0,17 & 8,64 \\
\hline Original & 8,67 & 1,39 & 0,17 & 8,31 \\
\hline Adap recurso 4 (PE/LE/LI) & 7,75 & 1,24 & 0,17 & 7,24 \\
\hline $\begin{array}{l}\text { Original } \\
\text { Adap recurso } 5 \text { (GR/PS/LI) }\end{array}$ & - & - & - & - \\
\hline $\begin{array}{l}\text { Original } \\
\text { Adap recurso } 6 \text { (GR/PS/AS) }\end{array}$ & - & - & - & - \\
\hline Original & 7,72 & 1,24 & 0,16 & 7,84 \\
\hline Adap recurso 7 (PE/OS/AS) & 10,16 & 1,63 & 0,16 & 9,89 \\
\hline Original & 9,81 & 1,57 & 0,18 & 8,89 \\
\hline Adap recurso 8 (GR/LE/LI) & 9,43 & 1,51 & 0,13 & 12,02 \\
\hline
\end{tabular}

Fonte própria

$\mathrm{O}$ recurso 5 adaptado, que corresponde às propriedades físicas tamanho (grande - GR), peso (pesado - PS) e textura (lisa - LI) e, também, o recurso 6 adaptado, em que as propriedades físicas foram: tamanho (grande - GR), peso (pesado - PS) e textura (áspera - AS) não foram realizadas pelo participante. Após cinco tentativas com cada recurso adaptado e não conseguindo a execução do movimento completo, ou seja, preensão, alcance e encaixe pelo participante, foram encerradas as tentativas e continuada a coleta de dados com os demais recursos adaptados.

Este dado evidenciou que a combinação entre tamanho grande e peso pesado não se mostrou satisfatória, desde a ação de preensão do recurso pedagógico, pois o participante mantinha o polegar em adução, substituindo-o pelos dedos indicador e médio e pouco contato dos dedos anular e mínimo para realizar a preensão. Também mantinha a flexão de punho com desvio ulnar. Estas al teraçóes biomecânicas da preensão dificultavam a ação e, consequentemente, o participante náo conseguia manter o recurso, soltando-o ao iniciar o movimento de alcance. Outros fatores a serem considerados referiram-se à presença de movimentos involuntários do tipo atetoide e a pontuação das escalas GMFMCS e MACS, em que ambas obtiveram a pontuação IV, indicando, respectivamente, comprometimento da função motora grossa e da habilidade manual. Vale ressaltar que o participante também apresentava dificuldade de manter controle de cabeça e tronco, sendo este último minimizado pelo uso da mesa com recorte. 
A preensão voluntária representa ação complexa, pois envolve várias fases, iniciando com a localização por meio da visão do objeto, controle cervical para acompanhamento visual, coordenação entre musculaturas sinergistas, como flexores e extensores dos membros superiores, controle de tronco para que as mãos estejam livres sem a função de apoio e preservação cinestésica (ZOPPA, 1998).

Outro fato a ser destacado é que na manutenção do membro superior, principalmente das articulações interfalangeanas e do punho em flexão, há diminuição considerável da força de preensão, o que também prejudicará a precisão ou destreza do movimento (GRANDJEAN, 1998). Desta forma, foi possível comprovar que os recursos pedagógicos grandes e pesados não são viáveis para a manipulação adequada de objetos por parte de crianças com paralisia cerebral que tenham as características motoras semelhantes à do participante, principalmente pela força de preensão diminuída e manutenção da flexão de punho e dedos.

A maioria das crianças com paralisia cerebral tem dificuldade em realizar atividades funcionais com os membros superiores, pois os movimentos são mais lentos em virtude da fraqueza muscular, rigidez mioarticular e coordenação deficitária (COLUCCINI et al., 2007), e também apresentam limitaçóes na dissociação de dedos (ELIASSON et al., 2006), o que dificulta ainda mais a preensão de objetos.

As características motoras do participante impediram a manipulação dos recursos pedagógicos grandes e pesados, devido à fraqueza muscular, coordenação motora deficitária, pela presença de movimentos involuntários do tipo atetoide e pela impossibilidade de realizar oponência do polegar para preensão do recurso, devido à manutenção do punho flexionado, o que impedia a dissociação dos dedos.

Assim como ocorreu com os resultados obtidos para a variável índice de retidão, também foi possível perceber os mesmos padrões de variação com os resultados do deslocamento escalar (s), uma vez que são variáveis dependentes, ou seja, para obtenção do valor do índice de retidão, divide-se o valor do deslocamento escalar (s) pelo valor da distância percorrida pelo membro superior, denominada, neste estudo, de alcance médio. Sendo o alcance médio um valor sempre constante, os padróes dos resultados obtidos não se diferem em relação a estas duas variáveis.

Portanto, foi possível analisar que houve uma variação considerável entre os valores obtidos com os recursos originais, sendo a média de 7,72 a 17,20 do índice de retidão e de $1,24 \mathrm{~m}$ a 2,75 m para o deslocamento escalar (s). Este fato indica inconsistência nas respostas obtidas nas ações de crianças com paralisia cerebral. Há uma variação nos resultados, sem que ocorra um padrão a ser estabelecido.

De acordo com Te Velde et al. (2005), indivíduos com paralisia cerebral apresentam déficit de planejar e controlar o ato motor durante a realização de uma atividade, o que dificulta a realização da mesma e o não surgimento de respostas mais coerentes e constantes, que deveriam acontecer.

Em relação aos recursos adaptados, foi possível observar que os recursos 1 (PE/LE/ AS), 3 (PE/PS/LI), 4 (PE/LE/LI) e 8 (GR/LE/LI) obtiveram melhores valores com relação ao índice de retidão e o deslocamento escalar (s) sendo, respectivamente, para o recurso 1 (9,50 
e $1,52 \mathrm{~m}), 3$ (9,11 e 1,45m), 4 (7,75 e 1,24m) e 8 (9,43 e 1,51m). Do mesmo modo como ocorreram as variaçóes dos resultados com os recursos originais há, também, entre os resultados obtidos com os recursos adaptados. Mesmo assim, é possível inferir que o tamanho pequeno foi o mais satisfatório, pois, entre os citados anteriormente, está presente em três deles, ou seja, nos recursos adaptados 1, 3 e 4. Em relação ao peso, dos quatro recursos adaptados, três deles são leves, ou seja, os recursos 1, 4 e 8.

Mas será possível afirmar que o recurso adaptado com as propriedades físicas sendo de tamanho pequeno, peso leve e textura lisa pode ser considerado melhor e ideal para que a criança com paralisia cerebral discinética, que é o caso do participante deste estudo, manipule com maior qualidade de movimento um objeto, um recurso pedagógico?

Há de se considerar a inconsistência de respostas obtidas frente à grande variação dos resultados das variáveis índice de retidão e deslocamento escalar (s) para a atividade de preensão, alcance e encaixe para o participante.

Também foi possível afirmar que houve variação de resultados no que se referiu à velocidade média, sendo esta maior para as repetições que o participante executou com o recurso original. A média variou de $0,16 \mathrm{~m} / \mathrm{s}$ a $0,26 \mathrm{~m} / \mathrm{s}$, enquanto que para os recursos adaptados variou de $0,13 \mathrm{~m} / \mathrm{s}$ a $0,18 \mathrm{~m} / \mathrm{s}$.

Audi (2006) verificou que alguns indivíduos com paralisia cerebral discinética, ao realizarem movimentos de ida e retorno de um alvo central e deslocado com o uso de pulseira estabilizadora com peso, realizaram menor deslocamento escalar, tanto com velocidades médias maiores, como menores. Assim, houve variação das velocidades médias com o uso de peso, enquanto o deslocamento escalar manteve-se estável.

Os dados obtidos neste estudo demonstraram que, na maioria das vezes, quanto maior foi a velocidade, maior também foi o deslocamento escalar ( $\mathrm{s}$ ), fato este comprovado com o recurso adaptado 2 (GR/LE/AS), em que ocorreu maior velocidade média $(18 \mathrm{~m} / \mathrm{s})$ e também maior média do deslocamento escalar $(\mathrm{s})(2,62 \mathrm{~m} / \mathrm{s})$.

A variável tempo $(\mathrm{t})$ despendida para o deslocamento também mostrou variaçóes de resultados, não ficando claro qual recurso se mostrou mais eficaz, ou seja, aquele cujo tempo (t) foi menor para a execução da atividade de preensão, alcance e encaixe para o participante. Assim, tanto para o recurso original, quanto para os adaptados, ora obtinham valores de tempo (t) despendido para o deslocamento menores, ora maiores.

Desta forma, como demonstrado para as variáveis anteriores, houve instabilidade nos valores obtidos, o que sugere inconsistência nas respostas de crianças com paralisia cerebral. Neste caso, é importante frisar que este fato pôde ser verificado com o participante, cujas características motoras mostraram-se comprometidas, sendo distônica, controle de cabeça e coordenação deficitária, presença de movimentos involuntários do tipo atetoide. Em relação às escalas GMFMCS e MACS, ambas obtiveram a pontuação IV, indicando comprometimento da função motora grossa e da habilidade manual, respectivamente.

Crianças com paralisia cerebral não realizam de forma adequada estratégias compensatórias para executar uma atividade motora. Desta forma, despendem mais tempo 
para a ação motora, principalmente naquelas relacionadas a atividades manuais em relação às crianças com desenvolvimento típico (ELIASSON; GORDON, 2000; HUNG; CHARLES; GORDON, 2004).

Em relação à estatística analítica com a utilização do teste de Wilcoxon para amostras pareadas, os resultados não foram significantes quando comparados os recursos originais com seus respectivos recursos adaptados. A Tabela 2 demonstra os valores da estatística com a comparação dos recursos originais e os adaptados para o índice de retidão, deslocamento escalar $(s)$, velocidade média $(\mathrm{Vm})$ e tempo $(\mathrm{t})$, em segundos, despendido para o deslocamento da ação de preensão, alcance e encaixe do participante.

Tabela 2 - Resultados do teste de Wilcoxon para os recursos originais com os adaptados, referentes ao índice de retidão, deslocamento escalar $(\mathrm{s})$, velocidade média $(\mathrm{Vm})$ e tempo $(\mathrm{t})$, em segundos, despendidos para o deslocamento

Valor de p - Teste de Wilcoxon

\begin{tabular}{|c|c|c|c|c|c|}
\hline $\begin{array}{l}\text { Comparaçáo entre os recur- } \\
\text { sos originais e os recursos } \\
\text { adaptados }\end{array}$ & $\mathbf{n}$ & $\begin{array}{l}\text { Índice de } \\
\text { retidáo }\end{array}$ & $\begin{array}{l}\text { Deslocamento } \\
\text { escalar (s) }\end{array}$ & $\begin{array}{l}\text { Velocidade } \\
\text { Média }(\mathrm{Vm})\end{array}$ & Tempo $(t)$ \\
\hline Ori recurso 1 & 5 & & & & \\
\hline Adap recurso 1 (PE/LE/AS) & 5 & 0,313 & 0,313 & 1,000 & 0,063 \\
\hline Ori recurso 2 & 5 & & & & \\
\hline Adap recurso 2 (GR/LE/AS) & 5 & 0,188 & 0,188 & $0,0,63$ & 0,063 \\
\hline Ori recurso 3 & 5 & & & & \\
\hline Adap recurso 3 (PE/PS/LI) & 5 & 0,125 & 0,125 & 0,188 & 0,125 \\
\hline Ori recurso 4 & 5 & & & & \\
\hline Adap recurso 4 (PE/LE/LI) & 5 & 0,625 & 0,625 & 1,000 & 0,313 \\
\hline Ori recurso 5 & & & & & \\
\hline Adap recurso 5 (GR/PS/LI) & - & - & - & - & - \\
\hline Ori recurso 6 & & & & & \\
\hline Adap recurso 6 (GR/PS/AS) & - & - & - & - & - \\
\hline Ori recurso 7 & 5 & & & & \\
\hline Adap recurso 7 (PE/PS/AS) & 5 & 0,813 & 0,813 & 0,813 & 0,438 \\
\hline Ori recurso 8 & 5 & & & & \\
\hline Adap recurso 8 (GR/LE/LI) & 5 & 0,813 & 0,813 & 0,063 & 0,313 \\
\hline
\end{tabular}

Fonte própria

Em relação à significância estatística analítica para comparação entre os recursos originais e, depois, entre os recursos adaptados, ou seja, como amostras dependentes, foi realizada a análise de variância náo paramétrica de Friedmann, referente ao índice de retidão, deslocamento escalar $(\mathrm{s})$, velocidade média $(\mathrm{Vm})$ e tempo $(\mathrm{t})$ para o deslocamento na atividade de encaixe para o participante (Tabela 3). 
Tabela 3 - Resultado da variância não paramétrica de Friedmann entre os recursos originais, referente ao índice de retidão, deslocamento escalar $(\mathrm{s})$, velocidade média $(\mathrm{Vm})$ e tempo $(\mathrm{t})$ para o deslocamento na atividade de encaixe para o participante

Valor de $\mathrm{p}$ - variância não paramétrica de Friedmann

\begin{tabular}{l|l|l|l|l|l}
\hline $\begin{array}{l}\text { Comparaçáo entre os recursos } \\
\text { originais }\end{array}$ & $\mathbf{n}$ & $\begin{array}{l}\text { Índice de } \\
\text { retidáo }\end{array}$ & $\begin{array}{l}\text { Deslocamento } \\
\text { escalar }(\mathbf{s})\end{array}$ & $\begin{array}{l}\text { Velocidade } \\
\text { Média }(\mathbf{V m})\end{array}$ & Tempo (t) \\
\hline $\begin{array}{l}\text { Original - recurso 1 } \\
\text { Original - recurso 2 }\end{array}$ & & & & & \\
$\begin{array}{l}\text { Original - recurso 3 } \\
\text { Original - recurso 4 } \\
\text { Original - recurso 7 } \\
\text { Original - recurso 8 }\end{array}$ & 30 & 0,0748 & 0,0748 & $<0,0001^{*}$ & 0,2034 \\
\hline
\end{tabular}

* significante

Fonte própria

A única variável que mostrou resultado significante foi a velocidade média $(\mathrm{Vm})$. Isto indica diferença entre os valores obtidos, quando da realização das repetiçóes com o recurso original pelo participante, mas todas as outras variáveis mantiveram-se estáveis frente às repetições realizadas com o recurso original. Assim, a velocidade média $(\mathrm{Vm})$, sendo maior ou menor, não apresentou influência direta sobre melhor qualidade de movimento do membro superior, pois o índice de retidão não obteve resultado significante.

O estudo de Audi (2006) demonstrou que houve variação das velocidades médias com o uso de pulseira estabilizadora com peso para os movimentos de ida e retorno de um alvo central e deslocado, mas o deslocamento escalar (s) manteve-se estável, o que sugere a não interferência da velocidade para melhor alcance de um objeto.

Em relação à comparação dos recursos adaptados entre si, ou seja, com as modificaçóes das propriedades físicas, a Tabela 4 demonstra os resultados significantes de p para as variáveis índice de retidão, deslocamento escalar e tempo $(\mathrm{t})$ despendido para o deslocamento.

Tabela 4 - Resultado da variância não paramétrica de Friedmann entre os recursos adaptados, referente ao índice de retidáo, deslocamento escalar $(\mathrm{s})$, velocidade média $(\mathrm{Vm})$ e tempo $(\mathrm{t})$ para o deslocamento na atividade de encaixe para o participante

Valor de p - variância não paramétrica de Friedmann

\begin{tabular}{l|c|c|c|c|c}
\hline $\begin{array}{l}\text { Comparaçáo entre os } \\
\text { recursos adaptados }\end{array}$ & $\mathbf{n}$ & $\begin{array}{c}\text { Índice de } \\
\text { retidão }\end{array}$ & $\begin{array}{c}\text { Deslocamento } \\
\text { escalar (s) }\end{array}$ & $\begin{array}{c}\text { Velocidade } \\
\text { Média (Vm) }\end{array}$ & Tempo (t) \\
\hline $\begin{array}{l}\text { Recurso Adap 1 } \\
\text { Recurso Adap 2 } \\
\text { Recurso Adap 3 }\end{array}$ & & & & & \\
$\begin{array}{l}\text { Recurso Adap 4 } \\
\text { Recurso Adap 7 } \\
\text { Recurso Adap 8 }\end{array}$ & 30 & 0,111 & 0,111 & 0,185 & $0,0291^{*}$ \\
\hline
\end{tabular}

* significante

Fonte própria 
No que se refere às comparações entre os recursos adaptados, somente a variável tempo $(\mathrm{t})$ mostrou resultado significante. O tempo despendido para o deslocamento está diretamente relacionado ao gasto energético para a realização da atividade, ou seja, quanto maior o tempo, maior será o dispêndio de energia. Por isso, faz-se necessário o ajuste do tempo do movimento para a realização de determinada ação motora (WEIR, 1994).

Desta forma, o participante, por ter o diagnóstico de paralisia cerebral discinética, em que o tônus é flutuante e, consequentemente, o aparecimento de movimentos involuntários do tipo atetoide, há dispêndio de energia acima do esperado para a realização de uma ação motora. Por isso, é relevante a análise da variável tempo despendido para o deslocamento na atividade em questão.

No que tange à comparação entre os recursos adaptados para a variável tempo ( $\mathrm{t}$ ) despendido para o deslocamento, foi possível constatar que o recurso 4 apresentou valores mais favoráveis em relação aos demais.

Tabela 5 - Valores estatísticos (variância não paramétrica de Friedmann) para as comparaçóes entre o recurso 4 com os demais, referente ao tempo $(\mathrm{t})$ despendido para o deslocamento para o participante

\begin{tabular}{l|c}
\hline Comparação entre o recurso 4 com os demais & Valor de p \\
\hline & \\
Recurso 1 e 4 & 0,2022 \\
Recurso 2 e 4 & $0,0025^{*}$ \\
Recurso 3 e 4 & 0,1438 \\
Recurso 7 e 4 & $0,0373^{*}$ \\
Recurso 8 e 4 & $0,0064^{*}$ \\
& \\
\hline
\end{tabular}

*significante

Fonte própria

$\mathrm{O}$ recurso $4(\mathrm{PE} / \mathrm{LE} / \mathrm{LI})$, em relação à variável tempo, foi significante quando comparado com os recursos 2 (GR/LE/AS), 7 (PE/PS/AS) e 8 (GR/LE/LI). Portanto, parece que os recursos adaptados, cujo tamanho foi considerado grande, neste estudo, não foram satisfatórios, uma vez que os recursos 2 e 8 apresentam esta característica e os recursos 5 e 6 , de tamanho grande e peso pesado, não foram realizados pelo participante. Mas será possível chegar à conclusão de que o recurso 4 foi o melhor manipulado pelo participante?

Deve-se considerar que, mesmo com este resultado, houve muitas variaçóes, principalmente nos valores obtidos entre as repetiçóes realizadas com o recurso original e com os recursos adaptados, não sendo possível afirmar que o recurso adaptado 4 foi o melhor manipulado com menor gasto energético pelo participante.

Na paralisia cerebral discinética, estão presentes movimentos involuntários e posturas inadequadas, devido à coordenação motora deficitária e alteraçóes na regulação do tônus. Há déficit na programação e execução eficiente dos movimentos voluntários, na coordenação de 
movimentos automáticos e na manutenção de postura (SCHWARTZMAN, 2004). Assim, devido a tais características, principalmente em relação à dificuldade de programação e execução de movimentos voluntários adequados, o participante apresentou inconsistência nas respostas motoras do membro superior de maior habilidade para as atividades de preensão, alcance e encaixe, propostas neste estudo.

\section{Consideraçóes finais}

O participante não realizou a atividade proposta com os recursos 5 (grande, pesado e liso) e 6 (grande, pesado e áspero). Assim, ficou evidente que a combinação entre tamanho grande e peso pesado não se mostrou satisfatória, desde a ação de preensão do recurso pedagógico.

Além disso, foi possível verificar instabilidade considerável nos valores obtidos, tanto para o recurso original, como para os outros recursos adaptados para as variáveis índice de retidão, deslocamento escalar ( $\mathrm{s}$ ) e tempo despendido para o deslocamento $(\mathrm{t})$. Este fato indicou inconsistência nas respostas obtidas pelas açóes motoras do participante. As características motoras evidenciaram comprometimentos mais graves, com a presença de flutuação de tônus, controle de cabeça e coordenação deficitárias, presença de movimentos involuntários do tipo atetoide. Além disso, por meio da GMFMCS e MACS, o participante obteve, para ambas as escalas, o nível IV, indicando comprometimento da função motora grossa e da habilidade manual.

Desta forma, há a comprovação de que crianças com paralisia cerebral com manifestaçóes clínicas mais graves apresentam dificuldades em realizar estratégias compensatórias adequadas para executar uma atividade motora e, por isso, as respostas aparecem instáveis e inconsistentes.

\section{REFERÊNCIAS}

ARAÚJO, R.C.T.; LORENZINI, M.V. A educação psicomotora como atividade lúdica para crianças com deficiência física. Revista Brasileira de Educação Especial, Marília, v. 3, n. 2, p. 63-71, 1995.

AUDI, M. Estudo comparativo do comportamento motor de membro superior em encefalopatas que fazem uso de pulseira estabilizadora. 2006. 112 f. Dissertação (Mestrado em Educação). Faculdade de Filosofia e Ciências, Universidade Estadual Paulista, Marília. 2006.

BRACCIALLI, L.M.P. Influência da utilização do mobiliário adaptado na postura sentada de indivíduos com paralisia cerebral espástica. 2000. 118 f. Tese (doutorado). Faculdade de Educação Física, Universidade Estadual de Campinas, Campinas, 2000.

CARVALHO, R.P. A influência da postura corporal no movimento de alcance manual em lactentes de 4 meses de vida. 2004. 117 f. Dissertação (Mestrado em Fisioterapia). Centro de Ciências Biológicas e da Saúde, Universidade Federal de São Carlos, São Carlos, 2004.

COLUCCINI, M. et al. Kinematic characterization of functional reach to grasp in normal and in motor disabled children. Gait and Posture, Oxford, v. 25, p. 493-501, 2007.

CRUZ, D. M. C; EMMEL, L. M. G. Pesquisas sobre preensão em crianças normais e crianças com paralisia cerebral. Arquivos Brasileiros de Paralisia Cerebral, São Paulo, v. 1, n. 3, p. 4-11, 2005.

ELIASSON, A.; GORDON, A. M. Impaired force coordination during object release in children with hemiplegic cerebral palsy. Developmental Medicine and Child Neurology, Oxford, v. 42, p. 228-234, 2000. 
ELIASSON, A.C. et al. Development of hand function and precision grip control in individuals with cerebral palsy: a 13-year follow-up study. Pediatrics, Vermont, v. 118, n. 4, p. 1226-1236, 2006.

ELIASSON A. C. et al. The Manual Ability Classification System (MACS) for children with cerebral palsy: scale development and evidence of validity and reliability. Developmental Medicine and Child Neurology, v.48, p. 549-554, 2006.

GRANDJEAN, E. Manual de ergonomia: adaptando o trabalho ao homem. Porto Alegre: Artes Médicas, 1998.

HAND grip span. In: CONSUMER AND COMPETITION POLICY DIRECTORATE. Specific Anthropometric and strength data for people with dexterity disability. London: Department of trade and industry, August, 2002, p. 34-37. Disponível em: www.bis.gov.uk/assets/biscore/consumer-issues/ docs/c/10-1255. Acesso em: 10 jan. 2010.

HIRATUKA, E; MATSUKURA, T. S. Sistema de classificação da função motora grossa para paralisia cerebral. 2007. Disponível em:

http://canchild.ca/Default.aspx?tabid=195. Acesso em 29 de Outubro de 2011.

HUNG, Y.; CHARLES, J.; GORDON, A.M. Bimanual coordination during a goal-directed task in children with hemiplegic cerebral palsy. Developmental Medicine and Child Neurology, Oxford, v. 46, p. 746-753, 2004.

KISHIMOTO, T.M. O jogo e a educação infantil. São Paulo: Pioneira, 1994.

LORENZINI, M.V. Brincando a brincadeira com a criança deficiente: novos rumos terapêuticos. São Paulo: Manole, 2002.

MARTIN, M.C.; JÁUREGUI, M.V.G; LÓPEZ, M.L.S. Incapacidade motora: orientaçóes para adaptar a escola. Porto Alegre, RS: Artmed, 2004.

PAIVA, P.C. Influência da textura do recurso pedagógico em atividades de encaixe realizadas por alunos com paralisia cerebral. 2007. 104 f. Dissertação (Mestrado em Educação). Faculdade de Filosofia e Ciências, Universidade Estadual Paulista, Marília, 2007.

REGANHAN, W.G. Recursos e estratégias para o ensino de alunos com deficiências: percepção de professores. 2006. 216 f. Dissertação (Mestrado em Educação). Faculdade de Filosofia e Ciências, Universidade Estadual Paulista, Marília, 2006.

SCHWARTZMAN, J.S. Paralisia cerebral. Arquivos Brasileiros de paralisia cerebral, São Paulo, v. 1, n. 1, p. 4-17, 2004.

TEIXEIRA, E.; ARIGA, M.Y.; YASSUKO, R. Adaptaçôes. In: TEIXEIRA, E. et al. (Org.).Terapia ocupacional na reabilitaçâo física. São Paulo: Roca, 2003. p. 129-173.

TE VELDE, A.F. et al. Planning and control in a manual collision avoidance task by children with hemiparesis. Motor Control, Quebec, v. 9, p. 417-738, 2005.

WEIR, P.L. Object property and task effects on prehension. In: BENNETT, K.M.B; CASTIELLO, U. Reach to grasp movement. Oxford: Elsevier Science, 1994, p.129-150.

ZOPPA, A.C.L. Terapia ocupacional em paralisia cerebral espástica. In: SOUZA, A.M.C.;

FERRARETTO, I. (Org.). Paralisia cerebral: aspectos práticos. 2. ed. São Paulo: Memnon, 1998. p. 231-242.

Recebido em: 07/03/2012

Reformulado em: 23/11/2012

Aprovado em: 18/03/2013 